\title{
Differentiation in pay for performance within organizations: an occupational perspective
}

Article

Accepted Version

Williams, M., Zhou, Y. and Zou, M. (2021) Differentiation in pay for performance within organizations: an occupational perspective. International Journal of Manpower, 42 (4). pp. 537-555. ISSN 0143-7720 doi: https://doi.org/10.1108/IJM-012020-0038 Available at https://centaur.reading.ac.uk/92337/

It is advisable to refer to the publisher's version if you intend to cite from the work. See Guidance on citing.

To link to this article DOI: http://dx.doi.org/10.1108/IJM-01-2020-0038

Publisher: Emerald

All outputs in CentAUR are protected by Intellectual Property Rights law, including copyright law. Copyright and IPR is retained by the creators or other copyright holders. Terms and conditions for use of this material are defined in the End User Agreement.

www.reading.ac.uk/centaur

\section{CentAUR}


Central Archive at the University of Reading

Reading's research outputs online 


\section{Differentiation in Pay for Performance Within Organizations: An Occupational Perspective}

Purpose: This article addresses the question of why organizations do not uniformly apply pay for performance (PFP) throughout the organization, focusing on the wider occupational structure in which they and the jobs they create are embedded. We propose a model of 'occupational differentiation' whereby the probability of a job within a given organization having PFP increases with levels of monitoring difficulty and requisite human asset specificity characterizing the occupation to which a job belongs, being highest in occupations characterized by high levels of both (generally managerial and professional occupations).

Design/methodology/approach: Using the Workplace Employment Relations Survey (a nationally-representative matched employer-employee dataset for Britain), this paper investigates this question for all 350 occupations delineated by the UK's Office for National Statistics using regression methods that adjust for other confounding factors such as demographic factors and workplace fixed-effects.

Findings: We find organizations 'occupationally differentiate' the use of PFP in ways consistent with the model i.e., PFP is most likely to be found in occupations characterized by both high monitoring difficulty and high requisite human asset specificity (mainly managerial and professional occupations) and least likely in occupations scoring low in both. The finding holds across PFP types (individual, group, organizational), whether organizations are large or small, and hold across most industrial sectors.

Research limitations/implications: The main implication of this study is that organizations appear to be taking into consideration whether the wider profession to which a job belongs when implementing PFP, irrespective of their own HRM strategies and organizational context. There are a few limitations to this study, with the main one being that empirical support is only 
found in the private sector. The public sector appears to be beyond the reach of the model, where PFP is generally rarer. A second limitation is that the dataset is from 2011 and only covers a single country.

Practical implications: Given organizations appear to be implementing PFP based on occupation, this may lead to equity concerns as different groups are being treated differently within organizations based upon their occupational group.

Social implications: Since PFP jobs tend to pay more than non-PFP jobs and PFP prevalence has been growing, by being more likely to implement it for generally high-paid groups (generally higher managerial and professional occupations), PFP may contribute to wider pay differentials within and between organizations.

Originality/value: By introducing the occupational-level of analysis and the differential nature of tasks across occupational groups, the model offers a new midrange, sociological perspective to understanding intra-organizational dynamics in PFP-use, and potentially HR practices more broadly.

\section{Key words:}

Compensation; Performance pay; HR differentiation; Occupations.

Wordcount: 7535 words (not including abstract, tables, and figures). 


\section{Introduction}

Pay for performance (PFP) is a critical tool used by organizations to align interests of employees to theirs. Understanding where and why organizations make use of such pay systems has been a key concern in the compensation literature. While the literature is rich in accounts mapping and explaining inter-organization dynamics in PFP-use, research exploring intra-organization dynamics has been lacking. However, an emerging set of statistical regularities does in fact suggest organizations differentiate the use of PFP within their boundaries and that this differentiation takes on an occupational form (Bayo-Moriones et al. 2013; Yanadori and Kang 2011) suggesting it is something in need of explanation. There are wider implications to studying this question for practice and for society. For instance, previous research has shown that differential PFP-use within organizations can lead to poorer work attitudes (Marescaux et al. 2013), while other research has shown that not only do PFP jobs pay more (Green and Heywood 2016), the rise in PFP has contributed to growing wage inequality (Bryan and Bryson 2016).

In this article, we propose a model which suggests that who gets PFP within a given organization to a great extent depends on the characteristics of the occupation to which a job belongs. While previous research tended to focus on jobs (a collection of tasks), sociologists often focus on occupations (aggregations of jobs with functionally similar tasks). Building on the sociological theory of occupational class, a theory commonly used in sociology to denote socio-economic positions of advantage and disadvantage based on occupational position, we develop a straightforward model which suggests monitoring difficulty and requisite human asset specificity are differentially bundled across occupations. In this paper, difficulty of monitoring refers to the degree of difficulty in measuring, observing, and controlling the quality and quantity of tasks as they are performed (i.e., performance), while requisite human asset specificity refers to the degree to which tasks require specialist knowledge to do them and so 
the ease of replacing a worker to perform them (i.e., turnover costs). Given this expected differential bundling of these two task dimensions across occupations, PFP should be even more likely among jobs belonging to occupations characterized by high levels of both. Using a nationally-representative matched employer-employee sample of British workplaces, findings generally support the model.

There are at least two theoretical contributions to be made from introducing and validating an occupational perspective to understanding intra-organizational dynamics in PFPuse. First, by delving within the organization, such an exploration moves beyond the so-called 'universalistic' accounts of HR practices. The existing literature's focus on inter-organization variation implicitly assumes HR practices_including PFP — are applied fairly uniformly throughout the organization to one of intra-organization variation. In this sense, such a contribution offers a workforce differentiation perspective to PFP. Second, by drawing on sociological theories concerning the importance of the occupational structure for compensation and the employment relationship, we introduce a plausible theoretical account as to why the wider occupational structure that is common to all organizations is an important contingency factor for understanding the differential application of PFP within organizations. Although the occupational structure has long been mooted as an underexplored contextual factor in organizational research (Johns 2006), how and why it might affect the adoption of HR practices has not been explicitly theorized. In doing so, we address calls for the development of midrange theories in understanding the design of compensation systems (Heneman 2000; Gooderham et al. 2018). By introducing the broader occupational structure that is common to all organizations, we introduce a structural variable constraining agency (DiMaggio and Powell 1983) that is both intra- and inter-organizational. An occupational approach therefore has the potential to connect intra-organizational processes to the wider macro environment and vice versa with respect to PFP, and perhaps HR practices more broadly. 


\section{Differentiation in PFP Within Organizations}

PFP refers to additional bonus payments on top of base pay based on either individual, team, organizational performance, or some combination. ${ }^{1}$ PFP aims to increase performance and retain better performing staff. A key concern in the literature has been mapping how PFP-use varies across organizations, focusing on structural factors such as unionization, sector, and national contextual factors (Gooderham et al. 2018). These inter-organizational accounts implicitly assume decisions on whether to implement PFP (as well as other HR practices more generally) are taken at the organizational-level and have very little to say in terms of which groups receive and which groups do not receive PFP within the organization once adopted. A conventional focus within this literature has therefore been on identifying critical organizationlevel and national-level factors determining the design of compensation systems. Strategic choice theorists, for instance, predict that a major determinant of pay systems between organizations is the degree of competition in an organization's product market (Schuler and Jackson 1987), perhaps implying little or unimportant variation within organizations.

An emerging set of research findings suggest employers systematically differentiate PFP across occupational groups within organizations (Bayo-Moriones et al. 2013; Yanadori and Kang 2011). These studies have only focused on single industrial sectors and a handful of occupations, so it is not yet clear whether differentiation in pay systems across occupations occurs more widely. However, the basis of the decisions of who gets PFP and who does not within organizations has neither been theoretically mapped nor empirically tested directly. We build upon the sociological theory of occupational class which implies the nature of the occupational task environment is a substantively important determinant of PFP within organizations, independent of organizational and industrial context. Our primary contribution

\footnotetext{
${ }^{1}$ Thus our paper is not about piece-rates.
} 
in this article is providing a simple theoretical account of the dividing lines along which differentiation in PFP occurs by introducing the occupation-level as a significant consideration, in line with sociological theories that have long emphasized as important for understanding the differentiation in compensation and employment relationships in the labor market (Liu and Grusky 2013; Goldthorpe 2007).

\section{Difficulty of monitoring}

The first area of the task environment we consider concerns difficulty of monitoring. That is, the degree of difficulty in measuring, observing, and controlling the quality and quantity of tasks as they are performed (i.e., performance). Related constructs such as the difficulty in monitoring effort have been a primary variable in the influential principal-agent theory (Eisenhardt 1989). In general, prior findings show that PFP is more likely in job roles where the tasks are difficult to monitor and control. Many studies have focused on senior executivesan occupation whose tasks are particularly difficult to closely monitor given the their multifaceted and varied nature, and control, given the position of senior executives at the top of organizational hierarchies. When studies focus on regular employees, they find that managerial-type duties also predict PFP-use. For instance, DeVaro and Kurtulus (2010) find that authority delegated to employees increases the probability of PFP within a nationalrepresentative survey of British workplaces.

Difficulty of monitoring tasks is about more than having managerial duties and authority, however. It is about the design of the job and its tasks more broadly. Eisenhardt (1988) on a sample of retail workers showed how jobs with low spans of control and simple tasks were more likely to pay by time, whereas jobs with wide spans of control and complex tasks were more likely to have PFP. Fernie and Metcalf (1998) found that in call centers where employees were less closely monitored, employers were more likely to offer PFP jobs. Call 
centers that had designed tasks to be simple and routine implemented sophisticated electronic monitoring mechanisms and so were more likely to pay by time.

Given the quite varied occupations covered in previous studies, together, the factors they highlight as being important can be interpreted through the lens of a more general taskbased underpinning of PFP decisions. As insightful as previous findings are, individual studies have tended to focus on only either a single or handful of occupations or a single industry. This could be attributed to the lack of theoretical models on the sorts of tasks that are inherently difficult to monitor a priori (Prendergast 1999), which hampers a more general understanding of which sorts of jobs or occupations (by way of the tasks they contain) are more likely to adopt PFP. Nonetheless, given the foregoing evidence, we expect task monitoring difficulty to play an important role in differentiating the use of PFP within organizations. Specifically, we hypothesize:

\section{Hypothesis 1. Monitoring difficulty is positively related to the use of PFP}

\section{Human asset specificity}

A second area of the task environment concerns the degree of requisite human asset specificity to do the tasks composing the job or occupation. An influential body of theory suggests that organizations often tailor their HR practices such as pay systems to specific job groups (Lepak and Snell 1999; 2002; Lepak et al. 2007), sometimes known as the 'HR differentiation' or the 'workforce differentiation' perspective (Becker, Huselid, Beaty 2009). In explaining why the applicability of different HR practices might be differentiated across job groups within organizations, this perspective emphasizes variation in the scope and nature of human capital typically used and required across job types within organizations, which in turn, map onto the type of employment relationship organizations try to foster with each type of job group, and so HR practices (Lepak and Snell 1999). Lepak and Snell (1999) derive a model of differentiation 
in 'HR architecture' and its correspondence with 'employment modes'. Drawing upon transaction cost economics, human capital theory, and the resource-based view of the firm, they develop a model of 'human resource architecture' with four corresponding 'employment modes': 'internal development', 'contracting', 'acquisition', and 'alliance'. The model predicts organizations differentiate their employment relationships, and so HR practices, according to broad classes of job roles which are inter alia those that are perceived as more central to revenue generation (Lepak and Snell 2002; Lepak et al. 2007).

Central to HR differentiation is what we call human asset specificity, which is generally understood to be the extent to which embodied knowledge and experience can be productively applied across different contexts, with specific human assets (or 'skills') only having productive value in a more restrictive set of contexts than those of a more general kind. For instance, it is a central feature in models of firm-specific training whereby training investments only have productive value for the firm providing it but not others. However, the concept can also be applied more broadly to refer to the degree to which productive value would be lost if any kind of specialist knowledge was transferred to another job or establishment (Goldthorpe 2007: 213) _ even if it might be productively employed in another job or establishment. In short, the degree of human asset specificity (in this broader usage of the term) is the turnover costs associated with specific job roles. For the incidence of PFP within organizations, this theory implies that the extent to which tasks require and benefit from accumulated and the accumulation of specialist knowledge to do them, across job groups provides the main basis to how organizations differentiate HR practices, while organizational factors are of only secondary importance.

Since implementing any HR practice entails additional costs (e.g., PFP payments and their administration), they are only adopted when the benefit outweighs the cost. This is generally more likely in the case for job groups characterized by tasks requiring high human 
asset specificity given turnover costs are higher in such situations (e.g., policies that aim to improve retention). Groups where the tasks do not require or benefit from high levels of human asset specificity are generally more expendable and this is reflected in the HR practices regulating their employment relationship (e.g., more insecure contracts). As a general theory of HR practices, HR differentiation theory is often tested against combinations of a broad array of HR practices (e.g., high involvement practices) which may include PFP among many other elements, and evidence is generally supportive (Lepak and Snell 2002; Lepak et al. 2007).

Although few studies have explored specifically pay systems with respect to the key tenets of HR differentiation theory (c.f. Bayo-Moriones et al. 2013), we expect requisite human asset specificity to do the tasks to be an important differentiator across job groups within organizations with respect to PFP. This is because one of the key purposes of PFP is to foster commitment and to retain employees, a need which is greater in job roles where there is scope for valuable specific human assets to make a difference to the productive value of the role by virtue of the sorts of tasks involved. Indeed, evidence shows bonus jobs tend to pay more overall than jobs without bonuses when holding other factors constant, including personspecific fixed-effects and taking into account the fact that some base pay may be substituted by the bonus (Green and Heywood 2016). PFP can therefore act as an 'efficiency wage' to help retain specific human assets and encourage further investment in them when these can add to productive value. Evidence does show that PFP jobs are associated with higher levels of organizational commitment and lower employee turnover (Bayo-Moriones and LarrazaKintana 2009), indicating that they often do fulfil this aim.

According to the HR differentiation perspective, then, PFP then would only be worth the cost in job groups where the typical tasks require and have more scope to develop valuable specific human assets by virtue of their tasks. In Lepak and Snell's (1999) terminology, we expect PFP, then, to be firmly within the 'internal development' employment mode of job roles 
characterized by high requisite human asset specificity. In job roles with tasks requiring only low requisite human asset specificity—where roles are easily filled with an equally productive worker from the external labour market (i.e., where turnover costs are low) - there is much less need for such costly pay systems. Following on from the foregoing, we therefore expect:

\section{Hypothesis 2. Human asset specificity is positively related to the use of PFP}

\section{Difficulty of monitoring, human asset specificity, and occupations}

The foregoing discussion suggests that PFP is implemented where tasks are difficult to monitor or where tasks require specific human assets to them. Two issues we seek to clarify are, first, the extent to which the two dimensions of monitoring difficulty and requisite human asset specificity are bundled across occupations (i.e., do job groups where tasks are difficult to measure and control as they are being performed also have greater requisite human asset specificity and vice versa), and secondly, whether the two dimensions might interact (i.e., does the effect of monitoring difficulty level on PFP probability vary according to requisite human asset specificity level and vice versa).

There is a long tradition in economic sociology which theorizes that occupations are deeply institutionalized bundles of jobs sharing similar tasks and rates of pay (Liu and Grusky 2013). The occupational structure, and associated occupational norms and isomorphism, can be thought of as an important structural variable that is common to all organizations (DiMaggio and Powell 1983), constraining agency. In forming our expectations about the relationship between occupations and PFP, we draw on a third theory, the sociological theory of occupational class. 'Occupational class' is a technical construct denoting a broad groups of occupations ('classes') sharing similar employment relations and is widely used by sociologists as a measure of socio-economic position (Goldthorpe 2007). Occupational class theory states that differences in monitoring difficulty and human asset specificity across occupations 
determine broad types of employment contract (Goldthorpe 2007). It further assumes that the two dimensions are differentially bundled together across occupations such that occupations involving tasks that are very difficult to monitor do not necessarily also have scope for high levels of human asset specificity and vice versa.

According to the theory, in occupational classes with both high monitoring difficulty and high requisite human asset specificity scope 'managerial and professional occupations'), employees are more difficult to directly control and are more costly to replace so organizations adopt a 'service relationship' which is characterized by an exchange of a more diffuse kind such that employees are salaried rather than paid hourly, job tenures are longer, and internal labor markets offer greater opportunities for advancement and retention. Conversely, in occupational classes with both low monitoring difficulty and low scope for human asset specificity 'manual and routine occupations') employees are easy to directly control and more costly to replace so organizations adopt 'labor contracts' which are characterized by an exchange of a more specific kind such that employees are hourly paid rather than salaried, have greater job insecurity, and offer little opportunities for advancement. In occupational classes with low (high) monitoring difficulty and high (low) requisite human asset specificity scope ('intermediate occupations'), organizations adopt 'mixed' employment relationships combining elements of the above two types (Goldthorpe 2007). Although the general service relationship/labour contract distinction has been repeatedly empirically validated (e.g., McGovern et al. 2007), scarce research has examined the assumption of whether the two task dimensions highlighted in the theory really are differentially bundled across the occupational categories ('classes') that are used to denote employment relationship types.

Since occupational class theory assumes monitoring difficulty and requisite human asset specificity are differentially bundled across occupations, we expect to observe this in the data. Furthermore, given this differential bundling, we expect the effect of monitoring difficulty 
to vary according to level of human asset specificity and vice versa. This is because PFP schemes involve their own costs (Prendergast 1999). As previously mentioned, costs include the additional payments themselves and their administration such as appraising or measuring performance. This means that two occupations with very different levels of monitoring difficulty may end up having similar PFP probabilities if they both involve very low human asset specificity scope. This is because simply replacing persistent poorly performing employees in low human asset specificity occupations is a cheaper than developing and administering a PFP scheme. For instance, the PFP probability of van drivers (high monitoring difficulty, low asset specificity) should be similar to hospital porters (low monitoring difficulty, low asset specificity) even though it is costlier to monitor tasks in the former than the latter because employees in both occupations have low scope to benefit from or for developing valuable specific human assets. The threat of replacement or the ability to use insecure contracts can reduce agency issues in such cases.

The same is also predicted for the other way around. There should be little difference in PFP probability between high and low asset specificity occupations when monitoring difficulties are very low. For instance, aircraft pilots and assembly line workers have very different scope for human asset specificity use or development while their monitoring difficulties are both (similarly) very low. Even though aircraft pilots require high levels of human asset specificity, there is very little need for PFP schemes given the organization can closely monitor their minute-to-minute, second-to-second performance. Organizations can use other ways to retain star performers such as non-pecuniary benefits or career ladders in occupations where human asset specificity is important but monitoring is easy. Thus although in general organizations differentiate PFP according to monitoring difficulty and requisite human asset specificity, the effects are much smaller at low levels of the other variable because of the costs involved in PFP schemes. 
By extension, the interaction effect we are proposing implies that PFP should be most likely found in occupations characterized by both high monitoring difficulty and high requisite human asset specificity. The marginal gain from a PFP scheme is even greater in these situations relative to situations where an occupation scores highly in just one of the two variables. Although previous empirical research in the PFP literature has implicitly identified an interaction between monitoring difficulty and requisite human asset specificity (DeVaro and Prasad 2015), it has rarely been tested. A graphical representation of our expectations of the interaction effect can be found in Figure 1. We expect PFP probability to be greatest in occupations falling into the upper-right quadrant and be lowest in the lower-left quadrant, being intermediate in the off-diagonals. More formally, we expect:

Hypothesis 3. Difficulty of monitoring and human asset specificity are differentially bundled across occupations such that they are only weakly correlated with one another.

Hypothesis 4. The effects of monitoring difficulty and human asset specificity depend on levels of each other such that PFP probability is greatest where both monitoring difficulty and human asset specificity are high, lowest where both are low, and low where levels of one is very low.

[FIGURE 1 ABOUT HERE]

\section{Data and analytical strategy}

\section{Data}

To address these hypotheses, we draw upon the 2011 Workplace Employment Relations Survey (WERS) (Department for Business, Innovation and Skills et al. 2015). WERS is a nationally-representative sample of around 2,000 British workplaces with 5 or more employees. The strength of WERS for our purposes is that participating workplaces were invited to randomly distribute an employee survey to up to 25 employees within them, yielding 
a matched employer-employee sample of around 20,000 employees nested within workplaces. WERS is considered the most authoritative survey of its kind in the world (van Wanrooy et al. 2013).

Given the matched employer-employer structure of WERS, it allows for an exploration on whether PFP is occupationally differentiated within workplaces, representing a strength over other studies which examine only the workplace-level or broad categories of employees within the workplace. After removing workplaces with a single employee respondent, workplaces with no employees reporting PFP, respondents younger than 20 and those older than 60 , and respondents with missing data on variables of interest, we are left with a sample of around 8,400 employees based in around 780 workplaces.

\section{Measures}

The primary focus is whether monitoring difficulty, human asset specificity scope, and their interaction predict receiving PFP for a given employee within a given PFP workplace. In the Survey of Employees component of WERS, sampled employees are asked 'Which of the following do you receive in your job here?' and are given various options relating to pay systems. We focus on three of them: (1) 'Payments based on your individual performance or output' (e.g., merit pay); (2) 'Payments based on the overall performance of a group or a team' (e.g., gain sharing); (3) 'Payments based on the overall performance of your workplace or organization (e.g., profit-sharing scheme)'. Respondents ticking any of (1) to (3) are classified as receiving PFP and is the main dependent variable, although we disaggregate the different forms of PFP and their combinations in a robustness analyses.

The main independent variables of interest are the tightness of supervision (a proxy for difficulty of monitoring) and the extent to which an employees' job requires specialist knowledge to perform it (a proxy for requisite human asset specificity). This information is 
derived at the occupational-level from the nationally-representative British Skills and Employment Surveys (SES) (Felstead et al. 2014). The SES has been collecting nationallyrepresentative information on a battery of job tasks - including measures of monitoring difficulty and the level of required specialist knowledge. Difficulty of monitoring is captured by the item: 'How closely are you supervised in your job?' with the possible responses 'Very closely', 'Quite closely', 'Not very closely', and 'Not at all closely' ranging from 1 to 4 . Human asset specificity is captured by the item: 'In your job, how important is specialist knowledge and understanding?' with the possible responses 'Essential', 'Very important', 'Fairly important', 'Not very important', and 'Not at all important/Does not apply'. These two items or ones similar to them have been shown in previous exercises to have good construct and criterion validity (McGovern et al. 2007; Williams 2017).

Responses to both items were reverse-coded and mean occupational-level scores from the pooled 2006 and 2012 SES mapped samples onto 3-digit occupation codes of sampled employees in WERS. ${ }^{2}$ We pool the two latest SES waves in order to have sufficient sample size since some occupations were found to not have been sampled in the 2012 wave (combined $\mathrm{N}=8,644)$. In both SES and WERS, occupations are recorded in the Office for National Statistics' 3-digit Standard Occupational Classification (SOC2000) schema which distinguishes 354 unique occupations, offering a fine-grained measure of the two occupational

\footnotetext{
${ }^{2}$ We also investigated using (i) the modal responses within each occupation and (ii) the percentage of respondents within an occupation reporting they are 'very closely supervised' and specialist knowledge as 'essential'. Results were qualitatively in the case of the latter but not the former (available from the authors). In the case of (i), the results were nonsignificant. Further investigation revealed that modal scores do not adequately represent the variation across occupations given all most all occupations share the same modal scores as monitoring difficulty is measured on a 4-point scale, while asset specificity is measured on a 5-point scale. We thank a reviewer for suggesting this robustness check.
} 
task dimensions. ${ }^{3}$ To facilitate interpretation, both items were standardized to have a mean of 0 and a standard deviation of 1 (z-scores). ${ }^{4}$

\section{Analytical strategy}

The analysis proceeds in three steps. In the first step, we descriptively analyze the distribution of PFP across the two key independent variables. We then explore how 4-digit occupations are clustered according to their monitoring difficulty and requisite human asset specificity scores to explore the extent to which they are differentially bundled across occupations, as assumed by occupational class theory, such that sufficient numbers of occupations should be found in all quadrants of Figure 1. In the second step, we shift to a multivariable approach and test our hypotheses net of controls. More specifically, we test a series of models to ascertain whether monitoring difficulty and requisite human asset specificity have independent effects on PFP and whether their effects depend on the level of the other, as we predict. In the third and final step, we present a series of robustness checks on our main results.

Since we are interested in understanding occupational differentiation in PFP within workplaces, in all multivariable analyses, we only focus on workplaces that have at least one PFP employee (about 50 per cent of workplaces). Additionally, within this subsample, we control for a large number workplace fixed-effects (one for each workplace). We therefore employ conditional fixed-effects logistic regression. Binary response methods such as the one we use are sometimes said to suffer from non-comparability of coefficients across differently specified models (Allison 1999). However, this issue only applies if one is interested in the underlying latent variable rather than the actual binary response itself (Kuha and Mills 2018).

\footnotetext{
${ }^{3}$ We also investigated collapsing these indicators by 2 -digit (25 categories) and 3-digit SOC (81 categories) codes and found qualitatively similar results (available from the authors). We thank a reviewer for suggesting this robustness check.

${ }^{4} \mathrm{We}$ also tried taking z-scores on just the sample of employees drawn from PFP workplaces and found qualitatively similar results (available from the authors). We thank a reviewer for suggesting this robustness check.
} 
Results employing linear probability models that do not suffer from this potential issue found qualitatively similar results (available on request). Since we are primarily interested in occupational-level independent variables, we also implement robust clustered standard errors clustered on 4-digit occupations. Since we use a sample survey, we also apply the survey design weights in all analyses to ensure representativeness of estimates. Finally, we convert the log odds ratios from the regressions to a probability interpretation to facilitate interpretation by calculating average marginal effects (underlying coefficients available on request).

In all multivariable analyses, we introduce a variety of standard control variables to scrutinize the associations uncovered: We include age (four categories), gender (dummy), whether reported being an ethnic minority (dummy), whether have any dependent children under 16 (dummy), the respondent's educational qualifications (five categories), job tenure (five categories), whether the respondent has supervision duties (dummy), whether part-time contract (working fewer than 30 hours per week) (dummy), and whether the contract is temporary (dummy). These controls are important as PFP-use has been shown to depend on certain individual-level factors which may correlate with occupation such as ethnicity.

\section{Results}

\section{Descriptive analysis}

Table 1 presents the information on the sample of employees in PFP workplaces (defined by whether a respondent receives PFP or straight pay). For comparison, information is also included on the subsample of employees in workplaces with no PFP as well as the combined sample in the final column. Within PFP workplaces (our population of interest), just over one in three employees received PFP. We find that PFP jobs have on average 0.25 standard deviations higher monitoring difficulty and 0.30 standard deviations higher requisite human 
asset specificity on average, while non-PFP jobs in PFP workplaces on average are lower than average along these two dimensions, providing preliminary support for Hypotheses 1 and 2 .

\section{[TABLE 1 ABOUT HERE]}

Having inspected the distribution of our key dependent variables, we now explore our two key independent variables a bit more to ascertain the extent to which they are analytically distinct constructs as predicted by Hypotheses 3 or whether they are two sides of the same coin. Figure 2 is a simple scatter plot of them. We find little evidence of 'bunching' of occupations along the diagonal of the two dimensions: high monitoring difficulty occupations are not necessarily high requisite human asset specificity occupations and vice versa-there appears to be a good level of dispersion. Indeed, both dimensions are only very weakly correlated with one another $(r=0.08, p=0.05)$. It appears they are indeed quite analytically distinct.

Nonetheless, there does appear to be definite clustering by occupation type, as suggested by occupational class theory. About 29 per cent of the combined sample (that is, employees in both PFP and non-PFP workplaces) are found in the upper-right quadrant — where we expect the probability of PFP to be greatest (Hypothesis 4). These are largely composed of managerial and professional occupations. The largest three occupations in this group are 'sales accounts and business development managers', 'vocational and industrial trainers and instructors', and 'other business and related associate professionals'.

Moving to the lower-left quadrant—where we expect the probability of PFP to be the lowest — we find most of these occupations are manual and routine (semi-routine and routine). The largest three occupations are 'care workers and home carers', 'postal workers, mail sorters, messengers and couriers', and 'sales and retail assistants'. This quadrant also accounts for about 29 per cent of the combined sample. 
The rest of the sample are found in the upper-left (26 per cent) and lower-right (15 per cent) quadrants. These are mostly 'intermediate occupations'. The largest three occupations in the upper-left are 'national government administrative occupations', 'secondary education teaching professionals', and 'nurses', while the largest three in the lower-right are 'other administrative occupations', 'cleaners and domestics', and 'personal assistants and other secretaries'.

\section{[FIGURE 2 ABOUT HERE]}

\section{Multivariable analysis}

The multivariable analysis begins with examining the determinants of PFP within PFP workplaces in Table 2. In Columns 1 and 2, we include, respectively, only monitoring difficulty and requisite human asset specificity. Average marginal effects in both columns are positive and significant. They both remain significant and in the same direction when including them both together in Column 4. When introducing the controls in Column 5, they are both significant and positive, although their magnitude reduces somewhat. Nonetheless, Hypotheses 1 and 2 are confirmed.

\section{[TABLE 2 ABOUT HERE]}

In substantive terms, in terms of monitoring difficulty, 'occupational hygienists and safety officers' (about one standard deviation above average) will have 2.6 percentage points higher probability than 'carpenters and joiners' (about average) of receiving PFP. In terms of requisite human asset specificity, the corresponding probability gap between 'IT strategy and planning professionals' (one standard deviation above average) and 'nursing auxiliaries and assistants' (about average) is about 5.8 percentage points. These may sound relatively small, but they are in the same order of magnitude as supervisory status, which has been the focus of 
several PFP papers (Devaro and Kurtulus 2010; 2015). Importantly, the two occupational task dimensions show independent effects, supporting Hypotheses 3.

Our final untested hypothesis is concerned with the interaction effects between monitoring difficulty and human asset specificity such that PFP probability will be greatest in those occupations characterized by both high monitoring difficulty and high requisite human asset specificity and that the effects of both will be small when the level of the other variable is very low (Hypothesis 4). To gauge this hypothesis, we do not report interaction effects given average marginal effects of interaction effects cannot be directly computed. ${ }^{5}$ To get handle on this, we report average marginal effects with 95\% confidence intervals of receiving PFP in Figure 3. Panel A reveals requisite human asset specificity only seems to have its positive effect on the probability of PFP when monitoring difficulty is not very low. In occupations where tasks are very easy to monitor, requisite human asset specificity makes little difference to PFP probability. In other words, even though an occupation may require highly specialist and difficult-to-replace knowledge, organizations are no more likely to implement PFP if the tasksare also easily supervised and directly controlled (i.e., occupations in the upper-left quadrant of Figure 2). Similarly, Panel B reveals that even though an occupation may be characterized by work that is difficult to monitor, organizations are no more likely to use PFP if tasks require little specialist and difficult-to-replace knowledge (i.e., occupations in the lower-right quadrant of Figure 2).

[FIGURE 3 ABOUT HERE]

\section{Heterogeneity by workplace size and industrial sector}

\footnotetext{
${ }^{5}$ In a robustness check using linear probability models where interaction effects can be computed, the interaction was found to be positive and significant (available from the authors). We thank a reviewer for suggesting this robustness check.
} 
We now explore heterogeneity in the statistical regularities revealed in the foregoing analysis. We present three alternative specifications to the main model in Column 5 in Table 2. First, we explore alternative ways of defining PFP. Columns 1 to 3 of Table 3 consider respectively the effect of monitoring difficulty and human asset specificity on detailed PFP systems (individual, group, and organization PFP). We find the same patterns hold as when considering whether an employee receives any one of them as in the main analysis. Column 4 examines whether an employee is subjected to two or more PFP types. These findings suggest monitoring difficulties and requisite human asset specificity not only predict whether an employee received PFP or not, but also the number of schemes they are subjected to.

\section{[TABLE 3 ABOUT HERE]}

In the second and third robustness checks, we examine whether the 'occupational differentiation' in PFP we have uncovered holds across different types of workplaces. We consider two important axes of workplace type with respect to PFP: workplace size and industrial sector (Table 4). Although we in effect treat them as control variables in the main analyses (through workplace fixed-effects), they could have important moderating effects on decisions to differentiate pay systems within organizations. Workplace size affects average workgroup size as well as the development level of the HR function. Since the marginal cost of implementing a pay schemes decrease as the number of employees covered grows, so does the cost of having several systems in a given workplace and differentiating them across job groups. As for industrial sector, strategic choice theorists trace the growth of PFP systems to the globalization of product market competition, which of course varies by sector. For workplace size, we find the same pattern of results as in the main analyses in Table 4. Interestingly, however, monitoring difficulty seems to have weaker effects in smaller workplaces, while requisite human asset specificity seems to have stronger effects in smaller workplaces. With respect to the former, this is likely because direct monitoring and control of 
tasks is much easier in smaller workplaces as supervisors likely have fewer subordinates. With respect to the latter, smaller workplaces tend to have fewer opportunities for advancement and personal development than larger ones due to less developed HR systems, therefore the retention motivation of PFP for staff in more specialist roles is likely stronger there than in larger workplaces. Regarding the hypothesized interaction effect, the patterns are in line with the general expectations across different workplace size categories (available on request).

\section{[TABLE 4 ABOUT HERE]}

For industrial sector (Table 4), however, we do find some departures. Monitoring difficulty and requisite human asset specificity seem to have no detectable effect in the public sector, but the other three sectors follow the expected patterns. This is perhaps because PFP has never been as developed in the public sector and the occupational concentration in the

public sector likely explains much of the generally lower rates (Bryson, Forth, and Stokes 2017). Nonetheless, the overall patterns of main effects and interaction effects are similar to our main analyses (available on request).

\section{Discussion and conclusions}

This article started out by arguing that while the compensation systems literature is replete with inter-organization accounts of compensation systems, they rarely offer much insight into what goes on beneath the organization-level. However, we also note that an emerging regularity in the small number of studies that focus on differentiation in the workplace takes on an occupational form (Bayo-Moriones et al. 2013; Yanadori and Kang 201). Drawing upon he sociological theory of occupational class, this article investigated the role of occupational characteristics in the use of PFP within a nationally-representative matched employeremployee dataset for Britain. Our basic argument is that the wider occupational structure in which jobs are embedded is important for understanding intra-organizational dynamics in PFP 
by way of the different kinds of tasks found in different occupations. Specifically, tasks are differentially bundled across occupations according to monitoring difficulty and requisite human asset specificity. These occupational task dimenions in turn positively and multiplicatively predict PFP-use within organizations. Even among different types of PFP, we find little difference in the structure of 'occupational differentiation' within workplaces-be they based on individual, team, or organizational performance. We also show that organizations generally differentiate PFP in this way across different workplace sizes and industrial sectors, although the public sector remains beyond the reach of the model we developed here.

Our article makes two main theoretical contributions. First, it provides an account on intra-organization dynamics in PFP-use, drawing on influential theories in the field. We believe the model we develop could help understand the dividing lines in HR differentiation, in particular for compensation systems. Second, by focusing on the wider occupational structure in which jobs are embedded (which are in turn a collection of tasks), we provide a midrange account of PFP. Despite prior calls to develop more midrange contextual theories in understanding compensation systems (Heneman 2000), models are lacking. The occupationallevel is particularly interesting since it cuts across the more conventional organizational, sectorial, and national levels of contextual analysis (Johns 2006). In doing so, we introduce a structural variable constraining agency (DiMaggio and Powell 1983) that is both intra- and inter-organizational. An occupational perspective offers a way of connecting micro processes with macro patterns. For instance, one reason for the growth in PFP might be technologicallyinduced shifts to occupations in the upper-right quadrant of Figures 1 and 2 (largely managerial and professional occupations). By clarifying the how and why PFP varies across occupational groups, we hope it can bring the attention to managers the constraining nature of the wider occupational structure in what they operate and that not only are organizations subjected to organizational isomorphism (DiMaggio and Powell 1983), but also perhaps occupational 
isomorphism. We hope that an occupational perspective will prove illuminating in this regard and recommend further integration with existing multi-level accounts in the compensation literature (e.g., Gooderham et al. 2018).

For future research, while the theories developed here suggest a particular compensation is used in situations where it most suited, and, as Larkin, Pierce, and Gino (2012: 1196) observe "firms often deviate from the most efficient systems and can make mistakes, in general the prevalence of systems and decisions is highly correlated with efficiency and effectiveness", this may not be the case much of the time. The effect of deviating from 'occupational norms' on performance outcomes therefore warrants further investigation, given PFP-use appears to be closely tied to occupation, more specifically, the sorts of tasks typically found in them. More generally, ooccupational differentiation in PFP within organizations may result in unhelpful negative attitudes between groups that are treated differently (Marescaux et al. 2013) as employees' equity concerns may be more closely tied to their organizational than wider professional environment. Finally, it has been established that PFP jobs pay more. Given our research finds that PFP is more likely to be found in jobs in occupations where monitoring difficulty and requisite human asset specificity is high, which also are generally higher-paying occupations (i.e., managerial and professional), it highlights that PFP has the potential to increase overall wage inequality through increasing differentials both between and within occupations. We highlight these as areas for future investigation.

\section{References}

Allison, P.D. 1999. Comparing logit and probit coefficients across groups. Sociological Methods \& Research 28(2): 186-208. 
Bayo-Moriones, A., Galdon-Sanchez, J.E., and Martinez-de-Mortentin, S. 2013. The Diffusion of Pay for Performance Across Occupations. Industrial and Labor Relations Review 66(5): 1115-1148.

Bayo-Moriones, A. and Larraza-Kintana, M. 2009. Profit-sharing plans and affective commitment: Does the context matter? Human Resource Management 48(2): 207-226.

Becker, B., Huselid, M.A., and Beaty, M.W. 2009. The Differentiated Workforce: Transforming Talent into Strategic Impact. Cambridge, MA: Harvard Business School Press.

Bryan, M. and Bryson, A. 2016. Has performance pay increased wage inequality in Britain? Labour Economics 41: 149-161.

Bryson, A., Forth, J., Stokes, L. 2017. How much performance pay is there in the public sector and what are its effects? Human Resource Management Journal 27(4): 581-597.

DeVaro, J.D. and Kurtulus, F.A. 2010. An Empirical Analysis of Risk, Incentives, and Delegation of Worker Authority. Industrial and Labor Relations Review 64(4): 641-661.

DeVaro, J.D. and Prasad, S. 2015. The Relationship Between Delegation and Incentives Across Occupations: Evidence and Theory. The Journal of Industrial Economics LXIII(2): 0022-1821.

Department for Business, Innovation and Skills, Advisory, Conciliation and Arbitration Service, National Institute of Economic and Social Research (BEIS and NIESR). 2015. Workplace Employee Relations Survey 2011. [data collection]. 6th Edition. UK Data Service. SN: 7226. 
DiMaggio, P. and Powell, W. 1983. The Iron Cage Revisited: Institutional Isomorphism and Collective Rationality in Organizational Fields. American Sociological Review 48(2): 147-160.

Eisenhardt, K.M. 1988. Agency- and Institutional-Theory Explanations: The Case of Retail Sales Compensation, Academy of Management Journal 31(3): 488-511.

Eisenhardt, K.M. 1989. Agency Theory: An Assessment and Review, Academy of Management Review 14(1): 57-74.

Felstead, A., Gallie, D., Green, F., Inanc, H. 2014. Skills and Employment Surveys Series Dataset, 1986, 1992, 1997, 2001, 2006 and 2012. [data collection]. 2nd Edition. UK Data Service.

Fernie, S. and Metcalf, D. 1998. (Not) hanging on the telephone: payment systems in the new sweatshops. Centre for Economic Performance, LSE.

Gerhart, B. and Milkovic, G.T. 1990. Organizational Differences in Managerial Compensation and Financial Performance. Academy of Management Journal 33(4): 663691.

Goldthorpe J.H. 2007. Social class and the differentiation of employment contracts. In: Goldthorpe J.H. (ed) On Sociology (Volume Two): Illustration and Retrospect. Stanford, California: Stanford University Press, pp. 101-124.

Gooderham, P., Fenton-O'Creevy, M., Croucher, R., and Brookes, M. 2018. A Multilevel Analysis of the Use of Individual Pay-for-Performance Systems. Journal of Management 44(4): 1479-1504.

Green, C.P. and Heywood, J.S. 2016. Don't Forget the Gravy! Are Bonuses and Time Rates Complements? Industrial Relations 55(3): 490-513. 
Heneman, R.L. 2000. The changing nature of pay systems and the need for midrange theories of pay. Human Resource Management Review 10(3): 245-247.

Johns, G. 2006. The Essential Impact of Context on Organizational Behavior. Academy of Management Review 31(2): 386-408.

Kuha, J. and Mills, C. 2018. On Group Comparisons With Logistic Regression Models. Sociological Methods \& Research, forthcoming.

Larkin, I., Pierce, L., \& Gino, F. 2012. The psychological costs of pay-for-performance: Implications for the strategic compensation of employees. Strategic Management Journal 33(10): 1194-1214.

Lepak, D.P. and Snell, S.A. 1999. The human resource architecture: toward a theory of human capital allocation and development. Academy of Management Review 24(1): 31-48.

Lepak, D.P. and Snell, S.A. 2002. Examining the human resource architecture: the relationships among human capital employment, and human resource configurations. Journal of Management (28)4: 517-543.

Lepak, D.P., Taylor, M.S., Tekleab, A.G, Marrone, J.A., Cohen, D.J. 2007. An examination of the use of high-investment human resource systems for core and support employees. Human Resource Management 46(2): 223-246.

Liu, J. and Grusky, D. 2013. The payoff to skill in the third industrial revolution. American Journal of Sociology 118(5): 1330-1374.

Marescaux, E., Winne, S.D., and Sels, L. 2013. HR practices and affective organisational commitment: (when) does HR differentiation pay off? Human Resource Management Journal 23(4): 329-345. 
McGovern P., Hills M., Mills C., and White M. 2007. Market, Class and Employment. Oxford: Oxford University Press.

Milgrom, P. and Roberts, J. 1992. Economics, Organization and Management. Upper Saddle River, NJ: Prentice-Hall International.

Prendergast, C. 1999. Provision of Incentives in Firms. Journal of Economic Perspectives 37(1): 7-63.

Schuler, R.S. and Jackson, S.E. 1987. Linking competitive strategies and human resource management practices. Academy of Management Executive 1(3): 207-19.

Van Wanrooy, B., Beweley, H., Bryson, A., Forth, J., Freeth, S., and Wood, S. 2013. Employment Relations in the Shadow of Recession: Findings from the 2011 Workplace Employment Relations Study. Basingstoke: Palgrave Macmillan.

Williams, M. 2017. An old model of social class? Job Characteristics and the NS-SEC Schema. Work, Employment and Society 31(1): 153-165.

Yanadori, Y. and Kang S-C. 2011. Intra-firm differentiation of compensation systems: evidence from US high-technology firms. Human Resource Management Journal 21(3): 236-257. 
Tables and Figures

Table 1. Descriptive statistics (means)

\begin{tabular}{|c|c|c|c|c|c|}
\hline & \multicolumn{3}{|c|}{ PFP workplaces } & \multirow{2}{*}{$\begin{array}{c}\text { Non-PFP } \\
\text { workplaces }\end{array}$} & \multirow{2}{*}{$\begin{array}{c}\text { All } \\
\text { workplaces }\end{array}$} \\
\hline & Total & $\begin{array}{l}\text { PFP } \\
\text { jobs }\end{array}$ & $\begin{array}{c}\text { Non-PFP } \\
\text { jobs }\end{array}$ & & \\
\hline Pay for performance & 0.36 & 1.00 & 0.00 & 0.00 & 0.21 \\
\hline Individual & 0.21 & 0.58 & 0.00 & 0.00 & 0.12 \\
\hline Team & 0.11 & 0.32 & 0.00 & 0.00 & 0.07 \\
\hline Organizational & 0.18 & 0.50 & 0.00 & 0.00 & 0.10 \\
\hline Monitoring difficulty & 0.00 & 0.25 & -0.13 & 0.08 & 0.03 \\
\hline Human asset specificity & 0.06 & 0.30 & -0.07 & -0.16 & -0.03 \\
\hline Age 20 to 29 & 0.22 & 0.20 & 0.23 & 0.18 & 0.20 \\
\hline Age 30 to 39 & 0.25 & 0.29 & 0.23 & 0.23 & 0.24 \\
\hline Age 40 to 49 & 0.29 & 0.29 & 0.29 & 0.31 & 0.30 \\
\hline Age 50 to 59 & 0.23 & 0.22 & 0.24 & 0.28 & 0.25 \\
\hline Female & 0.48 & 0.41 & 0.52 & 0.63 & 0.54 \\
\hline Ethnic & 0.15 & 0.15 & 0.15 & 0.14 & 0.15 \\
\hline Dependent children & 0.40 & 0.43 & 0.38 & 0.41 & 0.41 \\
\hline Degree or higher & 0.34 & 0.43 & 0.30 & 0.35 & 0.34 \\
\hline A-levels & 0.12 & 0.13 & 0.12 & 0.12 & 0.12 \\
\hline GCSEs & 0.36 & 0.32 & 0.39 & 0.34 & 0.35 \\
\hline Other qualifications & 0.10 & 0.08 & 0.11 & 0.11 & 0.11 \\
\hline No qualifications & 0.05 & 0.03 & 0.07 & 0.06 & 0.06 \\
\hline Tenure $<1$ year & 0.13 & 0.12 & 0.13 & 0.12 & 0.12 \\
\hline Tenure $>=1$ years $<2$ years & 0.11 & 0.11 & 0.11 & 0.10 & 0.11 \\
\hline Tenure $>=2$ years $<5$ years & 0.25 & 0.24 & 0.25 & 0.26 & 0.25 \\
\hline Tenure $>=5$ years $<10$ & 0.25 & 0.25 & 0.25 & 0.24 & 0.24 \\
\hline Tenure $>=10$ years & 0.27 & 0.27 & 0.26 & 0.28 & 0.27 \\
\hline Supervisor & 0.33 & 0.39 & 0.30 & 0.34 & 0.34 \\
\hline Part-time & 0.16 & 0.10 & 0.19 & 0.25 & 0.20 \\
\hline Temporary contract & 0.06 & 0.03 & 0.07 & 0.08 & 0.07 \\
\hline \% sample & 54.6 & 17.3 & 37.3 & 45.4 & 100 \\
\hline
\end{tabular}

Notes: Data are weighted. 
Table 2. Multivariable analysis of occupational differentiation in pay for performance

\begin{tabular}{|c|c|c|c|c|c|}
\hline & $(1)$ & $(2)$ & (3) & $(4)$ & $(5)$ \\
\hline Monitoring difficulty & $\begin{array}{c}0.068^{* * * *} \\
(0.008)\end{array}$ & & & $\begin{array}{c}0.049^{* * * *} \\
(0.008)\end{array}$ & $\begin{array}{l}0.026^{*} \\
(0.011)\end{array}$ \\
\hline Human asset specificity & & $\begin{array}{c}0.118^{* * *} \\
(0.010)\end{array}$ & & $\begin{array}{c}0.104^{* * * *} \\
(0.010)\end{array}$ & $\begin{array}{c}0.058^{* * *} \\
(0.013)\end{array}$ \\
\hline Age 30 to 39 & & & $\begin{array}{l}0.070^{* *} \\
(0.022)\end{array}$ & & $\begin{array}{l}0.066^{* *} \\
(0.023)\end{array}$ \\
\hline Age 40 to 49 & & & $\begin{array}{l}0.071^{* *} \\
(0.024)\end{array}$ & & $\begin{array}{c}0.064^{*} \\
(0.026)\end{array}$ \\
\hline Age 50 to 59 & & & $\begin{array}{c}0.089^{* * * *} \\
(0.022)\end{array}$ & & $\begin{array}{c}0.080^{* * *} \\
(0.024)\end{array}$ \\
\hline Female & & & $\begin{array}{c}-0.062^{* * *} \\
(0.022)\end{array}$ & & $\begin{array}{c}-0.063^{* * *} \\
(0.023)\end{array}$ \\
\hline Ethnic & & & $\begin{array}{c}0.002 \\
(0.022)\end{array}$ & & $\begin{array}{c}0.011 \\
(0.024)\end{array}$ \\
\hline Dependent children & & & $\begin{array}{c}0.032^{*} \\
(0.015)\end{array}$ & & $\begin{array}{c}0.030 \\
(0.016)\end{array}$ \\
\hline Degree or higher & & & $\begin{array}{c}0.174^{* * *} \\
(0.022)\end{array}$ & & $\begin{array}{c}0.143^{* * * *} \\
(0.028)\end{array}$ \\
\hline A-levels & & & $\begin{array}{c}0.151^{* * *} \\
(0.026)\end{array}$ & & $\begin{array}{c}0.133^{\text {*** }} \\
(0.030)\end{array}$ \\
\hline GCSEs & & & $\begin{array}{c}0.088^{* * *} \\
(0.025)\end{array}$ & & $\begin{array}{l}0.074^{* * *} \\
(0.028)\end{array}$ \\
\hline Other qualifications & & & $\begin{array}{c}0.114^{* * * *} \\
(0.033)\end{array}$ & & $\begin{array}{l}0.100^{* *} \\
(0.036)\end{array}$ \\
\hline Tenure $>=1$ years $<2$ years & & & $\begin{array}{c}0.036 \\
(0.031)\end{array}$ & & $\begin{array}{c}0.038 \\
(0.033)\end{array}$ \\
\hline Tenure $>=2$ years $<5$ years & & & $\begin{array}{c}0.030 \\
(0.025)\end{array}$ & & $\begin{array}{c}0.033 \\
(0.026)\end{array}$ \\
\hline Tenure $>=5$ years $<10$ & & & $\begin{array}{c}0.049 \\
(0.025)\end{array}$ & & $\begin{array}{c}0.052 \\
(0.027)\end{array}$ \\
\hline Tenure $>=10$ years & & & $\begin{array}{c}0.042 \\
(0.027)\end{array}$ & & $\begin{array}{c}0.048 \\
(0.029)\end{array}$ \\
\hline Supervisor & & & $\begin{array}{c}0.060^{* * *} \\
(0.018)\end{array}$ & & $\begin{array}{c}0.036^{*} \\
(0.018)\end{array}$ \\
\hline Part-time & & & $\begin{array}{c}-0.012 \\
(0.024)\end{array}$ & & $\begin{array}{c}0.004 \\
(0.025)\end{array}$ \\
\hline Temporary contract & & & $\begin{array}{c}-0.138^{* * *} \\
(0.047) \\
\end{array}$ & & $\begin{array}{c}-0.150^{* * *} \\
(0.050)\end{array}$ \\
\hline Pseudo-R2 & 0.011 & 0.023 & 0.041 & 0.029 & 0.052 \\
\hline N employees & 8,471 & 8,471 & 8,471 & 8,471 & 8,471 \\
\hline $\mathrm{N}$ workplaces & 781 & 781 & 781 & 781 & 781 \\
\hline
\end{tabular}

Notes: Conditional fixed-effects logistic regression models with average marginal effects reported. Reference categories for age and tenure are 20-29 and <1 year respectively. Robust standard errors clustered on 4-digit occupations in parentheses. Data are weighted.

Statistical significance: $* \mathrm{p}<0.05, * * \mathrm{p}<0.01, * * * \mathrm{p}<0.001$. 
Table 3. Multivariable analysis of the occupational differentiation in detailed types of compensation systems

\begin{tabular}{lcccc}
\hline & $\begin{array}{c}(1) \\
\text { Individual PFP }\end{array}$ & $\begin{array}{c}(2) \\
\text { Team PFP }\end{array}$ & $\begin{array}{c}(3) \\
\text { Organization } \\
\text { PFP }\end{array}$ & $\begin{array}{c}(4) \\
\text { Multiple PFP }\end{array}$ \\
\hline Monitoring & $0.022^{*}$ & $0.037^{*}$ & $0.046^{* *}$ & $0.042^{* *}$ \\
difficulty & $(0.011)$ & $(0.016)$ & $(0.016)$ & $(0.014)$ \\
Human asset & $0.055^{* * *}$ & $0.061^{* *}$ & $0.047^{* *}$ & $0.048^{* *}$ \\
specificity & $(0.017)$ & $(0.024)$ & $(0.017)$ & $(0.017)$ \\
Workplace fixed & Yes & Yes & Yes & Yes \\
effects & & & & Yes \\
Controls & Yes & Yes & 0.071 & 0.095 \\
Pseudo-R2 & 0.040 & 0.049 & 4,499 & 3,507 \\
N employees & 7,010 & 4,274 & 386 & 284 \\
N workplaces & 617 & 360 & & Yes \\
\hline
\end{tabular}

Notes: Conditional fixed-effects logistic regression models with average marginal effects reported. Controls are omitted and are the same as Table 2. Robust standard errors clustered on 4-digit occupations in parentheses. Data are weighted.

Statistical significance: $* \mathrm{p}<0.05, * * \mathrm{p}<0.01, * * * \mathrm{p}<0.001$.

Table 4. Multivariable analysis of occupational differentiation in compensation systems by workplace size

\begin{tabular}{|c|c|c|c|c|c|c|c|}
\hline & (1) & $(2)$ & (3) & (4) & $(5)$ & (6) & (7) \\
\hline & \multicolumn{3}{|c|}{ Workplace size } & \multicolumn{4}{|c|}{ Industry } \\
\hline & $5-49$ & 50-199 & $200+$ & Manuf. & Services & Finance & Public \\
\hline Monitoring & $0.028^{*}$ & $0.033^{*}$ & $0.047^{*}$ & $0.029^{*}$ & $0.049^{*}$ & $0.041^{*}$ & 0.010 \\
\hline difficulty & $(0.014)$ & $(0.016)$ & $(0.021)$ & $(0.015)$ & $(0.020)$ & $(0.020)$ & (0.009) \\
\hline Human asset & $0.080^{* * *}$ & $0.066^{* *}$ & $0.051^{*}$ & $0.039^{*}$ & $0.074^{* *}$ & $0.063^{*}$ & 0.016 \\
\hline specificity & $(0.024)$ & $(0.022)$ & $(0.020)$ & $(0.020)$ & $(0.023)$ & $(0.029)$ & $(0.014)$ \\
\hline $\begin{array}{l}\text { Workplace fixed } \\
\text { effects }\end{array}$ & Yes & Yes & Yes & Yes & Yes & Yes & Yes \\
\hline Controls & Yes & Yes & Yes & Yes & Yes & Yes & Yes \\
\hline Pseudo-R2 & 0.103 & 0.056 & 0.056 & 0.078 & 0.065 & 0.091 & 0.058 \\
\hline $\mathrm{N}$ employees & 2,172 & 2,792 & 3,507 & 1,992 & 2,284 & 1,773 & 2,422 \\
\hline $\mathrm{N}$ workplaces & 257 & 229 & 295 & 166 & 242 & 158 & 215 \\
\hline
\end{tabular}

Notes: Conditional fixed-effects logistic regression models with average marginal effects reported. Controls are omitted and are the same as Table 2. Robust standard errors clustered on 4-digit occupations in parentheses. Data are weighted.

Statistical significance: $* \mathrm{p}<0.05,{ }^{* *} \mathrm{p}<0.01, * * * \mathrm{p}<0.001$. 


\section{FIGURES}

Figure 1. Monitoring difficulty, human asset specificity, and PFP

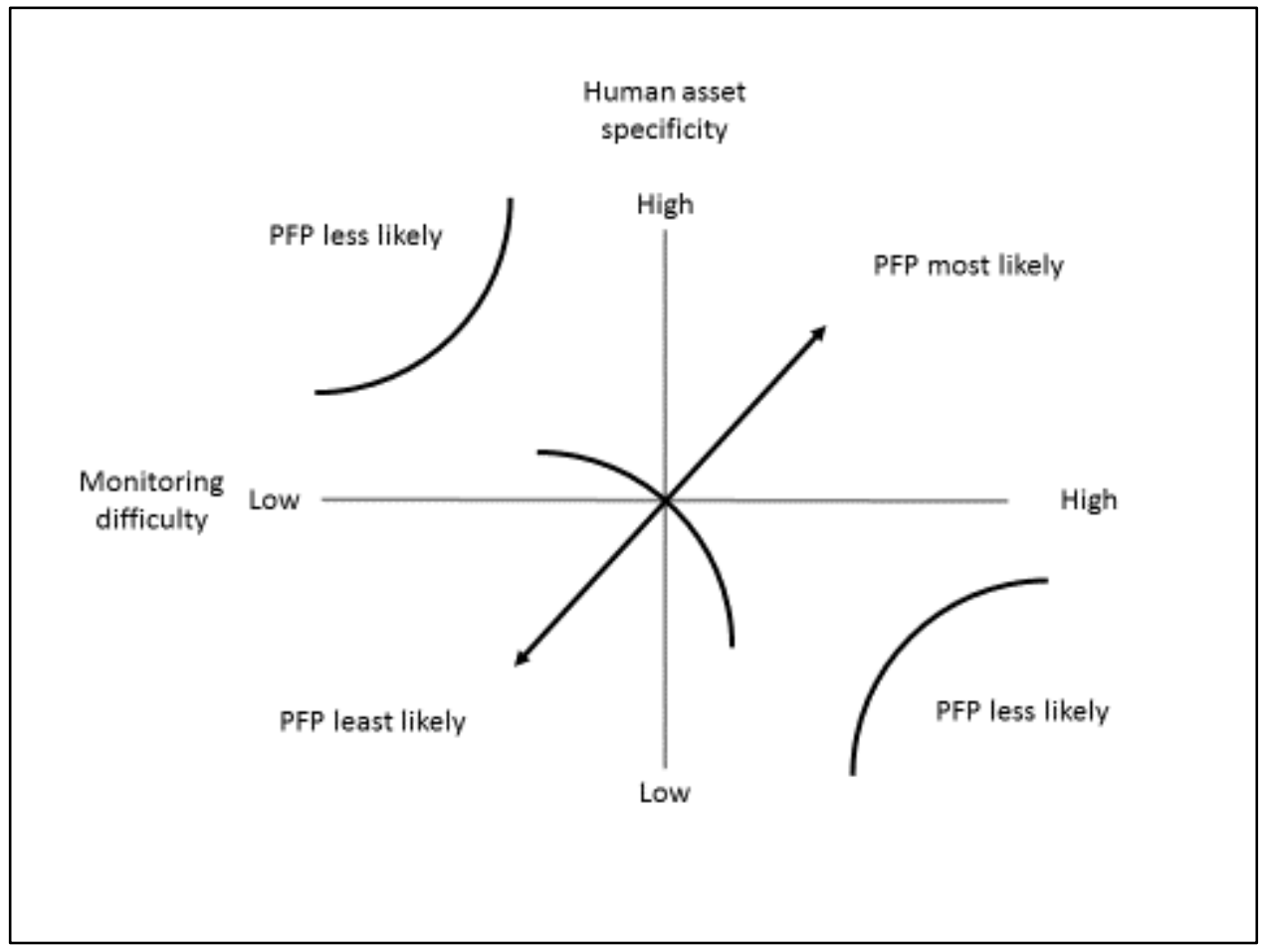

Notes: Adapted from Goldthorpe (2007).

Figure 2. Monitoring difficulty and human asset specificity across occupations

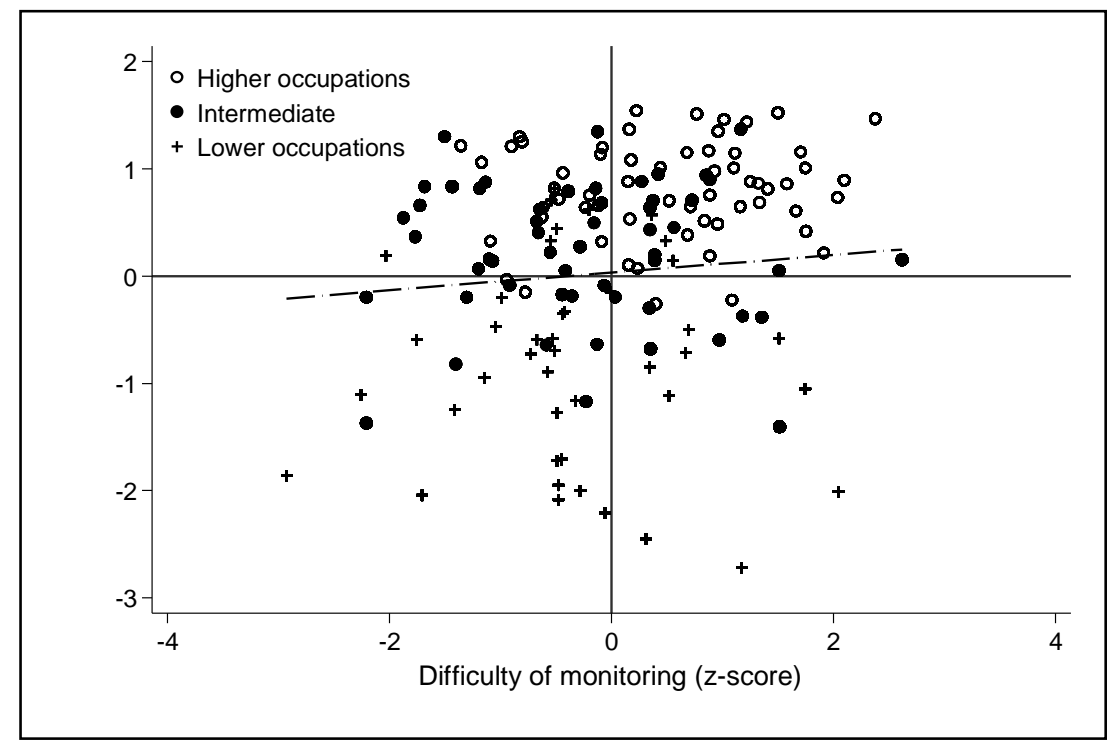

Notes: Each data point represents a 4-digit occupation. Data are weighted. 
Figure 3. The moderating effects of monitoring difficulty and human asset specificity on each other in PFP

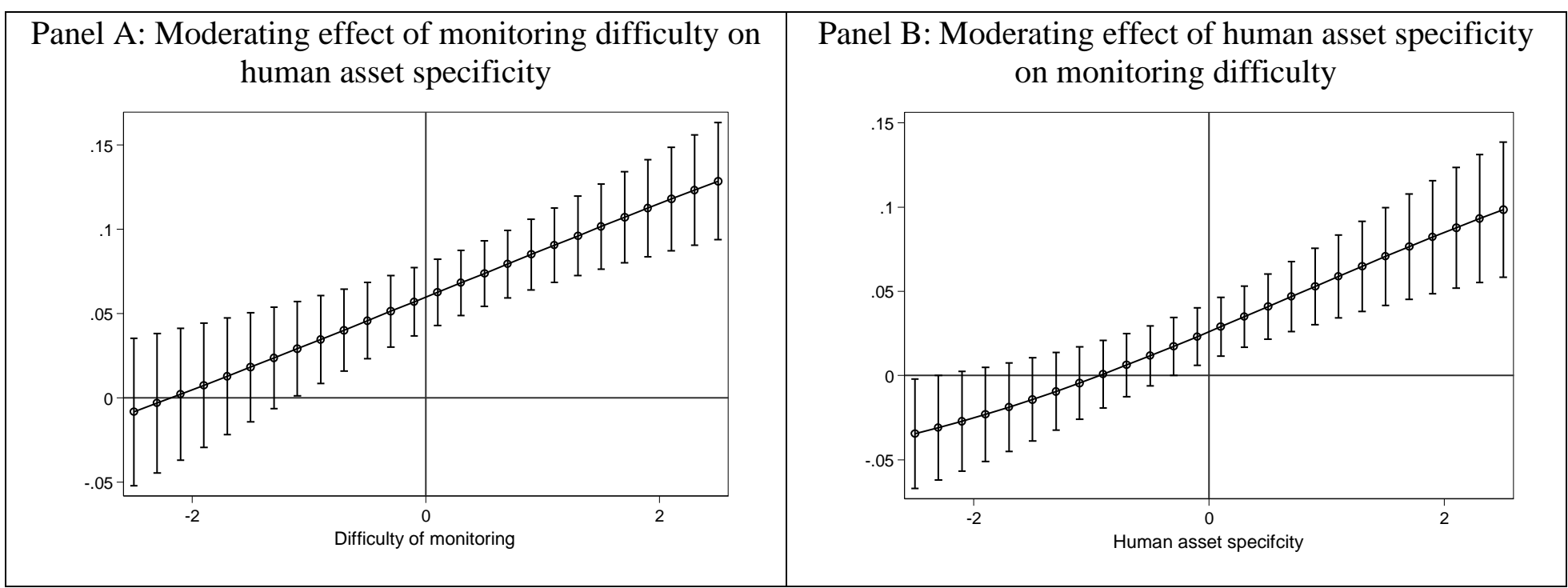

Notes: Post-estimations an identical model to Model 5 in Table 2 with the addition of an interaction term between monitoring difficulties and human asset specificity. The figures can be interpreted as the variability in average marginal effects (AME) over levels of the interacted variable. Vertical bars are 95\% confidence intervals. Data are weighted. 